\title{
Strategi Pengembangan Usaha Perempuan Penopang Ekonomi Keluarga Melalui Kelompok Usaha Bersama
}

\author{
NOVITA \\ Sekolah Tinggi Ilmu Ekonomi Riau \\ Jl. HR. Soebrantas Panam, Tuah Karya, Kec. Tampan, Kota Pekanbaru, Riau 28293 \\ E-mail : novita@lecturer.stieriau-akbar.ac.id
}

\begin{abstract}
Women as a support for the family economy are an interesting conversation, where being a pillar of the family economy makes women play a dual role. One role is to take care of the family and other roles to make a living to meet the needs of the family. Various reasons that caused this to occur include the divorce factor, then because the husband is left dead, also because the husband is in a state of helplessness (illness and deprivation). Working as a housemaid, then working as a laborer in the company, becoming a scavenger and many other efforts made also set up their own businesses. Data from pre-survey results show that $25 \%$ of women who are the backbone of the family are small entrepreneurs. However, because of the helplessness that was experienced, it caused the business to be less developed and even impressed on the road. What are the strategic steps they can take, this question is the answer in this study. Through qualitative research with a case study approach, namely the business group with beautiful graha and who became informants were group members and data were collected by interviews and analyzed descriptively. The results of the study show that the strategy carried out in the context of developing women's businesses is through producing unique business products and also establishing partnerships with the government.
\end{abstract}

Keywords: Women's Business, Partnerships and Unique Products.

Usaha ekonomi keluarga menjadi bagian yang penting mendapatkan perhatian, hal ini karena dari usaha menjadi sumber penghasilan keluarga dan hal ini juga menjadikan keberdayaan keluarga dapat diwujudkan. Pengembangan usaha ekonomi keluarga ini menjadi salah satu langkah straetegis yang diperoleh dan dapat dindalkan dalam keluarga.

Apabila dilihat terdapat banyak keluarga yang tidak mendapatkan nasib yang beruntung. Terkadang terdapat keluarga yang hanya mengandalkan belas kasian orang lain dan juga terkadang ada yang berusaha tanpa mengenal waktu sedangkan hasil yang diperolehnya hanya pas-pasan.

Perempuan sebagai penopang kehidupan keluarga menjadi salah satu fenomena yang dapat dijadikan pelajaran. Keluarga dan anggota keluarganya mengandalkan perempuan sebagai penopang kehidupan hidup mereka. Keterbatasan dari apa yang dimiliki dari sumber ekonomi menjadi perempuan kurang dapat diandalkan.

Usaha rumahan seperti warung harian, kemudian juga mengusahakan mencari barang rongsokan juga menjadi salah satu sumber pencaharian yang memang kondisinya ada di sekitar mereka dan berusaha mencari barang bekas dan menajualnya kembali. Selain itu juga bekerja paruh waktu pada pabrik juga mereka lalui.

Banyak penyebab yang menyebabkan mengapa perempuan yang menjadi penopang kehidupan keluarga. Hal ini seperti dikarenakan masalah perceraian rumah tangga, masalah ditinggal meninggal, masalah suami sakit dan bahkan memang karena ketidakmampuan kepala keluarga untuk mendapatkan penghasillan yang dapat memenuhi kebutuhan hiduip keluarga mereka.

Fenomena lainnya sebagaimana dijelaskan oleh Puspitasari, D. C. (2012) 
yang menjelaskan bahwa adanya modal sosial perempuan dalam peran penguatan ekonomi keluarga. Dimana perempuan dengan sumber daya yang dimiliki memiliki kemungkinan yang kuat untuk menopang ekonomi keluarga. Kemudian juga disampaikan oleh Astuti, M. (2017) yang mengatakan bahwa dengan menggali potensi sosial entrepenuership akan mampu untuk memberdayakan perempuan miskin dimana dengan adanya perempuan yang menyadari kondisi sesungguhnya yang mereka rasakan dan mereka akan dapat menggunakan apa yang mereka miliki untuk memberdayakan ekonomi keluarga.

Selanjutnya dijelaskan pula oleh Kristina, A. (2010) bahwa partisipasi Perempuan Dalam Perbaikan Perekonomian Keluarga dan Masyarakat menjadi sebuah kondisi nyata yang perlu mendapatkan perhatian dan bahkan memungkinkan untuk dilakukan dalam rangka perbaikan ekonomi keluarga. Hal ini menjadikan peran perempuan dalam kesejahteraan keluarga menjadi sangat bermakna.

Terdapat banyak contoh kehidupan pengusaha perempuan yang berhasil dan terus menjadi sumber ekonomi keluarga, seperti menurut penelitian Oktavianti, I. (2012) Perempuan Penjual Jamu Gendong Dalam Meningkatkan Kehidupan Sosial Ekonomi Keluarga. Usaha menjual jamu gendong menjadi salah satu bentuk usaha yang unik dan memungkinkan untuk dikembangkan.

Kemudian juga melalui kelembagaan koperasi seperti yang disampaikan Devanty, C. P., \& Saskara, I. A. N. (2017) bahwa Koperasi wanita memiliki peran dan andil besar dalam Upaya Pemberdayaan Perempuan Pada Koperasi Wanita. Melalui kelembagaan koperasi perempuan ini menjadikan perempuan berdaya dan mendapatkan banyak manfaat dalam mengembangkan usahanya.

Kemudian juga ada usaha perempuan sebagai pedagang pasar sebagaimana dijelaskan oleh Astuti, I.
(2010) bahwa adanya relasi Gender Pada Keluarga Perempuan Pedagang dimana terdapat banyak perempuan yang berjualan di pasar dan juga bekerja di sawah. Sebagaimana dijelaskan oleh Kristina, A. (2010) bahwa perempuan berpartisipasi dalam Perbaikan Perekonomian Keluarga dan Masyarakat dengan membantu para suaminya bekerja di sawah.

Banyak bukti keberhasilan perempuan dalam menopang ekonomi keluarga sebagaimana dijelaskan oleh Puspitasari, N., Puspitawati, H., \& Herawati, T. (2013) bahwa gender memiliki kontribusi ekonomi perempuan, dan kesejahteraan keluarga petani hortikultura dan juga menjadikan perempuan sebagai buruh tani yang tidak dibayar jerih payahnya dan keiklasan perempuan bekerja membantu keluarga juga mendapatkan apresiasi dalam berbagai perbincangan.

Juga tidak sedikit perempuan yang bekerja sebagai buruh seperti dijelaskan oleh Meydianawathi, L. G. (2005) Aktivitas Ekonomi Buruh Angkut Perempuan Di Pasar Badung. Juga hasil penelitian Wiasti, N. M. (2011). Dengan kajian mengenai perempuan berpeluh yang tak mengeluh: Studi tentang Perempuan Pedagang Sayur di Pasar Baturiti, Tabanan, Bali. Serta hasil kajian lainnya yang dilakukan oleh Sosan, I. (2010) yang menkaji tentang peran ganda Ibu Rumah Tangga yang bekerja sebagai Tukang Amplas Kerajinan Ukir Kayu. Para perempuan memiliki kegigihan dan keuletan serta keiklasan yang besar dalam membantu keluarga keluar dari masalah ekonomi dan menjadikan perempuan tidak kenal lelah untuk membuat kelaurga mereka bahagia dan sejahtera.

Kemudian juga adanya perempuan yang memiliki tanggungan keluarga yang besar dan juga menjadikan perempuan sebagai penentu keberhasilan keluarga. Mencari nafkah dan juga mendidik anggota keluarga. Sebagaimana hasil 
kajian Wibowo, D. E. (2011) tentang peran ganda perempuan dan kesetaraan gender. Juga hasil kajian Cahyadi, A. (2013) tentang konflik peran ganda perempuan menikah yang bekerja ditinjau dari dukungan sosial keluarga dan penyesuaian diri. Juga yang dilakukan oleh Puspitawati, H., Simanjuntak, M., \& Hayati, L. (2012) tentang kontribusi ekonomi dan peran ganda perempuan serta pengaruhnya terhadap kesejahteraan subjektif.

Dari pendapat tersebut menjelaskan bahwanya perempuan sebagai ibu rumah tangga juga berpotensi untuk terjun langsung mencari nafkah. Apalagi saat ini sudah masanya era emansipasi wanita sebagaimana dijelaskan oleh Fadilah, S. (2018) menjelaskan adanya kesetaraan gender sudah menjadi fenomena pergeseran peran ekonomi wanita dari tulang rusuk menjadi tulang punggung. Perempuan memiliki kemugkinan untuk dapat berhasil dan melihat kemampuanya dalam kehidupan.

Terdapat banyak strategi yang digunakan dalam rangka memberdayakan usaha perempuan sebagai tulang punggung keluarga seperti yang disampaikan oleh Daulay, H. (2006) bahwa adanya usaha yang dilakukan pemerintah dalam pemberdayaan perempuan. Juga disampaikan oleh Saugi, W., \& Sumarno, S. (2015) bahwa pemberdayaan perempuan dapat dilakukan melalui pelatihan pengolahan bahan pangan lokal. Melalui (1) Perencanaan partisipatoris terdiri dari identifikasi kebutuhan dusun dan penyiapan tim pengelola program dusun. (2) Pelaksanaan proses pemberdayaan melalui pelatihan dimulai dengan menyiapkan tim pengelola, membentuk kelompok usaha, menjalin kemitraan dengan pihak pemerintah dan swasta, membangun rumah produksi, mengajukan izin produksi, produksi dan pemasaran produk, melakukan studi banding ke industri rumah tangga, melakukan perbaikan dan diversifikasi produk, dilanjutkan dengan pelatihan massal, dan pendampingan. (3) Indikator keberhasilan pelatihan diantaranya adalah bertambahnya pengetahuan dan keterampilan warga, serta diperolehnya pendapatan hasil usaha penjualan produk. (4) Keberlanjutan program pemberdayaan perempuan ditunjukkan dengan telah adanya pengembangan produk atau variasi produk dan terbentuknya kemandirian tim.

Melalui kelembagaan juga dapat dilakukan pemberdayaan perempuan seperti yang dikatakan oleh Fahrudin, A. (2011) tentang Pemberdayaan, Partisipasi dan Penguatan Kapasitas Masyarakat yakni melalui berbagi model bimbingan sosial yang dapat digunakan dalam pengembangan, partisipasi dan penguatan kapasitas masyarakat. Sasaran bimbingan sosial adalah modal sosial yang ada dalam masyarakat, kelembagaan sosial dan partisipasi masyarakat. Sebagai sebuah model dan teknik dalam pengembangan masyarakat maka bimbingan sosial juga memiliki filosofi dan prinsip-prinsip yang harus dilaksanakan agar bimbingan sosial dapat mencapai tujuan. Tentunya peranan petugas bimbingan sosial dalam melaksanakan bimbingan sosial tersebut sangat penting dan strategis

Juga dijelaskan oleh Susilo, B. (2010)bahwa Lembaga (institution) adalah organisasi atau kaidah-kaidah, baik formal maupun informal yang mengatur perilaku dan tindakan anggota masyarakat tertentu baik dalam kegiatan-kegiatan rutin sehari-hari maupun dalam usahanya untuk mencapai tujuan tertentu. Lembaga-lembaga dalam masyarakat desa ada yang bersifat asli berasal dari adat kebiasaan yang turun temurun tetapi ada pula yang baru diciptakan baik dari dalam maupun dari luar masyarakat desa. Lembaga-lembaga adat yang penting dalam pertanian misalnya pemilikan tanah, jual beli dan sewa menyewa tanah, bagi hasil, gotong royong, koperasi, arisan dan lain-lain. Lembaga-lembaga ini mempunyai peranan tertentu yang diikuti dengan 
tertib oleh anggota masyarakat desa (Petani), dimana setiap penyimpangan akan disoroti dengan tajam oleh masyarakat. Dalam konteks pemberdayaan ekonomi perempuan petani, peran kelompok sangatlah penting karena, banyak permasalahan pembangunan di bidang pertanian yang tidak memungkinkan dipecahkan dengan pengambilan keputusan secara perorangan.

Dari uraian tersebut menjadi sebuah landasan berpikir berkenaan dengan masalah strategi pengembangan usaha perempuan sebagai tulang punggung keluarga melalu kelompok usaha bersama.

\section{METODE}

Melalui penelitian kualitatif dengan pendekatan studi kasus yakni pada kelompok usaha bersama graha permai dan yang menjadi informan adalah anggota kelompok dan data dikumpulkan dengan wawancara dan dianalisis secara deskriptif. Hal ini sesuai dengan pendapat Suroto, B., Novita, N., Pailis, E. A., Waldelmi, I., \& Fatkhurahman, F. (2017) bahwa penelitian kualitatif menjadi metoda yang efektif guna memecahkan masalah sosial.

\section{HASIL}

Hasil wawancara yang dilakukan dengan anggota kelompok usaha bersama (KUB) Graha Permai Kota Pekanbaru dan dikaitkan dengan teori yang ada dalam rangka pengembangan usaha perempuan dalam menopang kehidupan keluarga dihasilkan beberapa langkah strategis antara lain:

1. Mencari produk unik

Menghasilkan prodik unik menjadi langkah stratgis dimana dengan produk unik yang belum ada dipasaran akan menjadikan usaha yang dijalankan kurang mendapatkan persaingan dari para pesaing. Keunikan produk tersebut bisa dilihat dari:

\section{a. Rasa}

Produk dengan rasa yang berbeda dan menarik minat pembeli menjadikan produk lebih memberikan nilai tambah dan rasa ini juga menjadi sebuah perbedaan antara satu produk dengan produk lainnya.

b. Bentuk

Bentuk produk yang dibungkus dalam kemasan yang menarik dan juga memenuhi kebutuhan pelanggan akan menjadikan produk diminati oleh pelanggan itu sendiri.

c. Bahan baku

Keunikan bahan baku memberikan makna bahwa dengan adanya bahan baku yang berada di sekitar kita dan dimana untuk mendapatkan bahan baku dengan mudah akan menjadikan produk menjadi unik.

d. Harga

Kesemuanya tersebut seperti rasa, bentuk dan bahan baku membuat harga menjadi bersaing dengan pertimbangan para pelanggan untuk membeli produknya.

2. Menjalin kemitraan usaha

Menjalin kemitraan dalam rangka pemasaran dan juga dalam rangka memperkenalkan produk yang dihasilkan agar menyebar secara luas. Kemitraan ini dapat dilakukan melui:

a. Media sosial

Media sosial dapat digunakan sebagai upaya menyebarluaskan produk kepada para pelanggan. Selain itu juga, melalui media sosial produk akan dikenal dan akan mengundang minat para pembeli.

b. Pemerintah

Bermitra dengan pemerintah yakni dengan mendapatkan akses permodalan dan juga akses pelatihan serta bantuan modal serta untuk memasarkan produk melalui pameran-pameran pembangunan akan menjadikan produk lebih dikenal dan dapat mengundang daya tarik pasar.

c. Lembaga sosial

Lembaga sosial seperti lembaga amil zakat dan juga donatur lainnya 
dapat menjadikan sumber mitra dalam mendukung permodalan yang dibutuhkan.

\section{PEMBAHASAN}

Dari uraian berkenaan dengan masalah usaha memberdayakan perempuan sebagai tulang punggung keluarga ini menjadikan dunia usaha dan pemerintah perlu memberikan perhatian kepada perempuan sebagai tulang punggung. Hal ini menjadikan banyak manfaat diperoleh seperti melalui kreatifitas menghasilkan produk unik dengan kombinasi lokal dan juga melalui kemitraan dengan dunia usaha, pemerintah dan lembaga sosial.

Peran kelembagaan yang dilakukan yakni dengan dijadikan sebagai sarana untuk menghubungkan dan bertugas informasi dan pikiran. Kelompok usaha bersama akan dapat mengumpulkan para anggotanya untuk berdiskusi dan studi banding ditempat lain untuk mendapatkan berbagai bentuk produk olah yang unik. Selain itu juga, dunia usaha, pemerintah dan lembaga sosial akan mau memberikan bantuannya melalui lembaga. Karena bila dilakukan hanya sendiri-sendiri akan menjadi lembaga lemah dan tidak mudah mendapatkan bantuan.

Hal ini sejalan dengan apa yang dikatakan Rahman, F. (2017) bahwasanya tidak hanya memiliki modal kreatif, jalinan kemitraan juga akan dapat membuat usaha berhasil. Juga keberhasilan ini menciptakan kepuasan dalam menjalankannya sebagaimana dijelaskan oleh Fatkhurahman, F. (2016) bahwa usaha dapat membuat keberhasilan ekonomi juga kepuasan pelakunya. Juga ditegaskan dari hasil penelitian sebelumnya bahwa perlu adanya usaha kreatif dalam membangun ekonomi keluarga, Novita, N. (2016).

\section{SIMPULAN}

Berdasarkan uraian di atas, maka dapat diambil kesimpulan berkaitan dengan strategi pemberdayaan usaha perempuan sebagai penopang ekonomi keluarga yakni bahwa strategi yang dilakukan dalam rangka pengembangan usaha perempuan yakni melalui menghasilkan produk unik usaha dan juga menjalin kemitraan dengan pemerintah.

\section{DAFTAR RUJUKAN}

Astuti, I. (2010). Relasi Gender Pada Keluarga Perempuan Pedagang di Pasar Klewer Kota Surakarta (Doctoral dissertation, Universitas Sebelas Maret Surakarta).

Astuti, M. (2017). Pemberdayaan perempuan miskin berbasis pemanfaatan sumberdaya lokal melalui pendekatan sosial enterpreneurship (Studi kasus di daerah tertinggal, Kabupaten Pasaman, Sumatera Barat). Sosio Konsepsia, 17(3), 241-251.

Cahyadi, A. (2013). Konflik peran ganda perempuan menikah yang bekerja ditinjau dari dukungan sosial keluarga dan penyesuaian diri. Widya Warta, 36(02).

Daulay, H. (2006). Pemberdayaan perempuan (Studi kasus pedagang jamu di Gedung Johor Medan).

Devanty, C. P., \& Saskara, I. A. N. (2017). Peran Koperasi wanita dalam Upaya Pemberdayaan Perempuan Pada Koperasi Wanita di Kecamatan Blahbatuh Kabupaten Gianyar. E-Jurnal Ekonomi Pembangunan Universitas Udayana, 6(4).

Fadilah, S. (2018). Kesetaraan Gender: Fenomena Pergeseran Peran Ekonomi Wanita dari Tulang Rusuk menjadi Tulang Punggung. Mitra Gender (Jurnal Gender dan Anak), 1(1), 18-26. 
Fahrudin, A. (2011). Pemberdayaan, Partisipasi dan Penguatan Kapasitas Masyarakat. Bandung: Humaniora.

Fatkhurahman, F. (2016). Kepuasan Berwirusaha Melalui Kemauan Untuk Berkarya Usaha Industri Kecil. JEBI (Jurnal Ekonomi dan Bisnis Islam), 1(2), 143-153.

Kristina, A. (2010). Partisipasi Perempuan Dalam Perbaikan Perekonomian Keluarga dan Masyarakat. Pamator Journal, 3(1), 69-75.

Kristina, A. (2010). Partisipasi Perempuan Dalam Perbaikan Perekonomian Keluarga dan Masyarakat. Pamator Journal, 3(1), 69-75.

Meydianawathi, L. G. (2005). Kajian Aktivitas Ekonomi Buruh Angkut Perempuan Di Pasar Badung. PIRAMIDA.

Novita, N. (2016). Analisis Kreatifitas Kelompok Masyarakat Menghadapi Kondisi Ekonomi Rumah Tangga. Jurnal Daya Saing, 2(2), 150-159.

Oktavianti, I. (2012). Peranan Perempuan Penjual Jamu Gendong Dalam Meningkatkan Kehidupan Sosial Ekonomi Keluarga. Journal of Economic Education, 1(2).

Puspitasari, D. C. (2012). Modal sosial perempuan dalam peran penguatan ekonomi keluarga. Jurnal Pemikiran Sosiologi, 1(2), 69-80.

Puspitawati, H., Simanjuntak, M., \& Hayati, L. (2012). Kontribusi ekonomi dan peran ganda perempuan serta pengaruhnya terhadap kesejahteraan subjektif. Jurnal Ilmu Keluarga \& Konsumen, 5(1), 11-18.
Rahman, F. (2017). Peran Modal Manusia Dan Modal Investasi Terhadap Nilai Produksi Industri Kecil Di Kota Pekanbaru. Jurnal Benefita: Ekonomi Pembangunan, Manajemen Bisnis dan Akuntansi, 2(1), 1-9.

Saugi, W., \& Sumarno, S. (2015). Pemberdayaan perempuan melalui pelatihan pengolahan bahan pangan lokal.JPPM (Jurnal Pendidikan dan Pemberdayaan Masyarakat), 2(2), 226-238.

Sosan, I. (2010). Peran Ganda Ibu Rumah Tangga yang Bekerja sebagai Tukang Amplas Kerajinan Ukir Kayu. Komunitas: International Journal of Indonesian Society and Culture, 2(2).

Suroto, B., Novita, N., Pailis, E. A., Waldelmi, I., \& Fatkhurahman, F. (2017). Metode Penelitian Tindakan Solusi Bagi Masalah Sosial. Jurnal Diklat Review, 1(1), 25-28.

Susilo, B. (2010). Pemberdayaan Ekonomi Perempuan Tani Berbasis Kelembagaan. Jurnal Muwazah, 2(2).

Wiasti, N. M. (2011). Perempuan Berpeluh yang Tak Mengeluh: Studi tentang Perempuan Pedagang Sayur di Pasar Baturiti, Tabanan, Bali. PIRAMIDA.

Wibowo, D. E. (2011). Peran ganda perempuan dan kesetaraan gender. Universitas Pekalongan. 